\title{
SOBRE EL COPÓN DE ORO QUE SE FABRICÓ EN "CORRESPONDENCIA CON EL GUSTO Y BELLEZA” DE LA URNA DE VALADIER PARA EL MONUMENTO DEL JUEVES SANTO DE LA CATEDRAL DE SEVILLA
}

\section{ABOUT THE GOLDEN CIBORIUM OF THE VALADIER URN FOR THE MONUMENT OF THE MAUNDY THURSDAY OF THE SEVILLE CATHEDRAL}

\author{
Antonio Joaquín Santos Márquez \\ Universidad de Sevilla. España \\ ORCID: 0000-0002-7671-0936 \\ anjo@us.es
}

\begin{abstract}
En este artículo se estudia una importante obra del tesoro de la catedral de Sevilla: el copón de oro y pedrería que se hizo para reservar al Santísimo Sacramento en la urna de oro labrada por Luigi Valadier.

Palabras clave: orfebrería; siglo XVIII; Madrid; copón; catedral de Sevilla.

We study an important work of the treasure of the Seville Catedral in this paper: the gold and precious stones ciborium that was made to reserve the Blessed Sacrament in the gold urn made by Luigi Valadier.

Keywords: goldsmith; $18^{\text {th }}$ century; Madrid; ciborium; Seville Cathedral.
\end{abstract}

El conjunto de piezas de orfebrería del siglo XVIII que atesora la catedral de Sevilla es sin duda uno de los más sobresalientes del país. Su calidad y variedad hace que sea un destacado referente a la hora entender el devenir estético de la orfebrería española y europea durante este siglo. El grandioso trono de octavas -popularmente conocido como altar de plata-, la custodia del cardenal Solís, 
la propia urna del Jueves Santo de Valadier o el Lignum Crucis de oro son ejemplos relevantes que nos permiten comprender la dimensión alcanzada por este tesoro durante esta centuria, y su representatividad dentro del arte de la orfebrería barroca, rococó y neoclásica ${ }^{1}$. Y todo ello fue posible gracias a una serie de prelados y canónigos que invirtieron sus fortunas y volcaron su buen gusto en hacer de la catedral de Sevilla un centro de referencia de las innovaciones estéticas de la orfebrería durante este periodo.

Pues bien, precisamente sobre otra de estas piezas sobresalientes versará nuestro estudio, concretamente sobre el copón de oro y pedrería que se utilizó históricamente para reservar al Santísimo Sacramento en el monumento del Jueves Santo. A pesar de su importancia, esta majestuosa creación, al igual que muchas del tesoro catedralicio, adolece de un estudio profundo y sistemático, pasando incluso prácticamente desapercibida en los estudios que sobre la platería catedralicia se han hecho ${ }^{2}$. De ahí que seguidamente rescatemos del olvido esta obra de orfebrería, reconstruyendo todos sus pormenores históricos y valorando en su justa medida esta bella creación del final del rococó hispano.

La razón del porqué llegó tan rica pieza a la sede hispalense y su carácter sobresaliente en la producción de esta época está íntimamente relacionada con la presencia de otra importante creación antes mencionada y que sin duda deslumbró y fascinó a los capitulares del templo. Nos referimos a la urna de oro labrada por el orfebre romano Luigi Valadier, la cual fue presentada ante el cabildo el 6 de septiembre de 1771 (Figura 1). Se trataba de una donación del canónigo de la catedral hispalense don Jerónimo Ignacio del Rosal, y estaba predestinada a su uso exclusivo en el monumento del Jueves Santo de la catedral, y durante el año para reservar al Santísimo Sacramento en el sagrario del altar mayor, aquel que fuese labrado por Francisco de Alfaro en 1596; una idea esta última que consideramos bastante improbable que se pudiese llevar a cabo si tenemos en cuenta las medidas de la pieza y el sistema de apertura de la urna ${ }^{3}$. Sea como fuere, lo cierto es que la novedad estética y la soberbia calidad que mostraba la nueva obra aurífera debieron de ensombrecer sin duda al antiguo copón utilizado para estas mismas funciones litúrgicas. Ello al menos se desprende de la primera decisión que tomó el cabildo tras la llegada de este tabernáculo, donde se pedía a los señores de fábrica que, además de inventariar y bendecir la pieza, hicieran las pruebas necesarias para "colocar con comodidad en ella el copón que debe encerrar la forma

${ }^{1}$ Sin duda los estudios de referencia de estas piezas de platería de la catedral de Sevilla son Sanz Serrano, 1976: 146-195. Palomero Páramo, 1985: 575-645. Cruz Valdovinos, 1992.

2 Tan solo ha sido estudiada por Sanz Serrano, 1976: 158.

3 Palomero Páramo, 1985: 610-612 y 629. 
consagrada". No hacía mucho tiempo que el orfebre Juan Bautista Zuloaga había ejecutado este ciborio, también de oro y "con serafines y sobrepuestos esmaltados". Concretamente su hechura se llevó a cabo entre diciembre de 1744 y abril de 1745 y su coste ascendió a 14.004 reales y 24 maravedíes de vellón ${ }^{5}$. Una creación de Zuloaga que a su vez sustituyó a otro píxide de plata dorada y cincelada con pie redondo en el que se reproducían grabadas las insignias de la Pasión y presentaba una cruz como remate, según se describe en el inventario de $1668^{6}$, y que posiblemente fuese ejecutado en el mismo tiempo que la arqueta de plata que Hernando de Ballesteros el Viejo labró para el renovado monumento catedralicio en $1554^{7}$.

Ahora bien, parece que la prueba que se hizo con este copón barroco no fue del todo satisfactoria. El cambio de gusto que se había experimentado durante las dos décadas posteriores con la presencia arrolladora de la rocalla, y que precisamente se ejemplificaba con el bellísimo tabernáculo aurífero de Valadier, fue la razón fundamental para su suplantación por una pieza nueva acorde con estas novedades estéticas. Ello se expresa con claridad en el cabildo celebrado el 22 de noviembre de ese mismo año de 1771, cuando el mayordomo de la fábrica Pedro José del Campo hizo presente su parecer al respecto. En él explicaba que el referido copón de oro y esmaltes no era "correspondiente a la hermosura y pri-

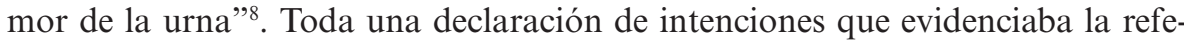
rida preferencia por la rocalla entre el gusto de los canónigos de la catedral y muy singularmente en el del propio fabriquero mayor, quien en este momento promovía la renovación rococó del trono de octavas de la catedral ${ }^{9}$. Por ello, en el seno del cabildo se habían hecho gestiones para su sustitución, pues esto es lo que se desprende del argumento que el mayordomo expuso seguidamente en el mismo auto para poder solventar el referido problema estético. Este anunció que un señor devoto y pío había recabado limosnas con las que tenía la intención de mandar hacer un copón de oro y pedrería para que hiciera "juego y correspondencia con el gusto y belleza de la urna", siempre que le diera permiso el cabildo y fuese

${ }^{4}$ Archivo de la Catedral de Sevilla (ACS), Secretaría, Autos capitulares, legajo 07183, 1771, f. 139r-v.

${ }^{5}$ ACS, Fábrica, Libros de cargo y data, legajo 4537, Cuentas particulares de Fábrica. Quentas de Juan Nicolas Cavaleri Funes, enero de 1743 a diciembre de 1746, s. f. Al margen se menciona la función de esta nueva obra y su fundición posterior en los siguientes términos: "este copón con su tapa que sirve de patena en virtud de auto capitular se dio al Devoto que dio otro tal copón con diamantes, rubíes y esmeraldas el cual se estrenó en el monumento deste año de 1772".

${ }^{6}$ ACS, Fábrica, Inventarios, legajo 09739, Inventario de las alhajas de la fábrica de la Santa Iglesia 1668, f. 39r.

7 Santos Márquez, 2008: 73.

${ }^{8}$ ACS, Secretaría, Autos capitulares, legajo 07183, 1771, f. 181r-v.

9 Santos Márquez, 2018a: 509-524. 
ayudado con la fundición del copón de Zuloaga. Un ofrecimiento que fue muy bien acogido por los capitulares, los cuales dieron su permiso y dispusieron que Pedro José del Campo informase al referido devoto de su consentimiento para que fabricase dicha dádiva en oro y piedras preciosas y que se invirtiese en ella la aludida pieza antigua ${ }^{10}$. Y si bien en este auto se nos ocultó la identidad del promotor de la obra, modestia por otra parte común entre los canónigos de la época, cuando finalmente el fabriquero registró el copón en el inventario mayor del templo se descubrió quién estuvo detrás de esta idea. Se trataba del mismo donante de la urna de oro, el canónigo Jerónimo Ignacio del Rosal "por cuya mano se dirigió dicha obra (y) a su celo y devoción se solicitaron dichas limosnas"11. No hay duda que lo que pretendió el mecenas de la urna de Valadier desde un primer momento fue conseguir que la pieza que acompañase a su donación romana estuviese a su altura y mostrase las novedades estéticas que tanto apreciaba. Y para conseguirlo, si bien no volvió a acudir a estos talleres italianos, buscó en un centro artístico más cercano, pero con el mismo nivel artístico, un artífice que lograse en poco tiempo labrar el nuevo copón para ser usado en los cultos del Jueves Santo del año 1772. Por esta razón, acudió a los talleres de platería de la Villa y Corte de Madrid que trabajaban al servicio de los Borbones, pues era sin duda el centro artístico más vanguardista de la España de su tiempo, nutrido por orfebres de muy diversa procedencia y donde las novedades europeas eran prontamente recibidas.

Así pues, entre fines de noviembre de 1771 y el 9 de abril de 1772 tuvo lugar el proceso de ejecución de este copón de oro con pedrería, ya que será en el capítulo celebrado ese último día cuando fue presentado ante los capitulares, causando gran admiración y determinándose su estreno "con la preciosa urna de oro el próximo jueves santo para depositar al señor en el monumento y que después se coloquen ambas piezas en el sagrario del altar mayor para que sirvan en el mismo ministerio todo el año" 12 . Por lo tanto, fue estrenado el Jueves Santo de dicho año, momento en el que el mayordomo de fábrica llevó a cabo su registro en el inventario catedralicio, teniendo a bien detallar todos los pormenores sobre la compra, tasación y coste de esta magistral obra ${ }^{13}$. Como dijimos, aquí será donde se indique que fue Jerónimo Ignacio del Rosal quien promocionó el copón y quien encargó su hechura en Madrid. Desafortunadamente no menciona el obrador al que acudió este notable mecenas, aunque sí se relacionaron los 13.267 reales con 20 maravedíes que entregó para su financiación, al igual que las limosnas que consiguió reunir para este mismo fin. En concreto, el canónigo lector Francisco

\footnotetext{
${ }^{10}$ ACS, Secretaría, Autos capitulares, legajo 07183, 1771, f. 181r-v.

11 ACS, Fábrica, Inventarios, legajo 09742, Inventario de las alhajas de la Sta. Iglesia Patriarcal de Sevilla 1770, ff. 33r-34r.

12 ACS, Secretaría, Autos capitulares, legajo 07184, 1772, ff. 67v-68r.

13 ACS, Fábrica, Inventario, legajo 09742, Inventario de las alhajas de la Sta. Iglesia Patriarcal de Sevilla 1770, ff. 33r-34r.
} 
Luis Vilar aportó 3.011 reales con 26 maravedíes, el referido mayordomo Pedro José del Campo ofreció 6.023 reales con 18 maravedíes, y el propio deán de la catedral Miguel Antonio Carrillo donó la suma más alta de todas, 22.588 reales y 8 maravedíes. Cantidades que, junto a lo obtenido de la venta del copón de Zuloaga que ascendió a 12.498 reales con 28 maravedíes, sumaron los 57.389 reales con 32 maravedíes que fue el montante final de esta costosa obra.

Asimismo, se anotaron los pormenores de su tasación, posiblemente realizada por el platero catedralicio de este momento, el mismo Juan Bautista $\mathrm{Zu}$ loaga que había visto desaparecer con esta obra una de sus primeras creaciones en la catedral ${ }^{14}$. En esta relación, como era de costumbre, se especificó todo el material empleado, las hechuras y las diferentes partidas económicas que les correspondían. En primer lugar, se emplearon 39 onzas y media de oro tanto en la obra como en el sobredorado de las partes de plata, siendo valoradas en 12.540 reales. El trabajo de su hechura alcanzó 3.555 reales y su cincelado concretamente 610 reales. Ello corresponde propiamente al copón de oro, pero en plata tenía labradas la copa interior que servía de patena para la comunión el Viernes Santo dispensada por el arzobispo, la chapa que cubría el reverso de la peana, las tuercas de sujeción interna y la base sobre la que estaban engastados los diamantes. Toda esta plata pesó 18 onzas y su coste ascendió a 396 reales. La pedrería estaba compuesta por 1.983 diamantes, 332 rubíes y 195 esmeraldas. Los primeros tuvieron un peso de 72 quilates y medio y su valor alcanzó los 22.293 reales; los rubíes pesaron 32 quilates y un ochavo y costaron 3.838 reales con 32 maravedíes; y los 31 quilates y medio de esmeraldas se tasaron en 4.016 reales con 8 maravedíes. El trabajo empleado en estas 2.510 piedras y su engarce en las diferentes partes del copón de oro fue valorado en 10.040 reales.

Y el resultado final afortunadamente aún se conserva y sin duda nos advierte de que fue un trabajo sobresaliente, pues tanto su cincelado en oro como los diferentes engastes de pedrería son de gran refinamiento y espectacularidad, delatando que estamos ante una de las creaciones más importantes de su tiempo. No obstante, hoy falta la copa que se incluía en la pieza originariamente y que tomaba gran relieve en la liturgia sacramental del Viernes Santo. Nos referimos al soporte de plata en forma de estructura troncocónica, o "copa interior que sostiene la patena deposito del sacramento", para la comunión que dispensaba el arzobispo en los oficios de esa tarde. En fotografías antiguas conservadas en la Fototeca del Laboratorio de Arte aún se contempla este elemento, que hoy día se ha retirado, encajándose la tapadera directamente a la copa (Figura 2).

Por lo tanto, lo que hoy podemos admirar en el museo catedralicio es únicamente la pieza de oro y pedrería (Figura 3). Su peana de planta circular presenta una pequeña pestaña decorada por una hilera de minúsculos diamantes

${ }^{14}$ Cruz Valdovinos, 1992: 386. 
facetados, tras la que arranca un friso igualmente decorado con esta misma piedra preciosa, pero ahora recreando una cadeneta de hojas de laurel. El cuerpo superior de la peana ligeramente acampanado muestra un delicado cincelado describiendo cuatro grandes cartouches formados por jugosos tallos enroscados con terminaciones encrespadas. Estas cartelas son las que sirven de base para unos ramilletes sobrepuestos de diamantes, rubíes y esmeraldas montados en plata. Reproduce el típico ramillete que fue tan recurrente en los modelos de broches de inspiración francesa de la segunda mitad del siglo, como aquellos que se conservan en la Biblioteca Nacional de Madrid, o en algunos petos reproducidos en el Libro de joyas de Nuestra Señora Santa María de Guadalupe ${ }^{15}$. Estos ramos son de diseño triangular, pues están compuestos por un tallo central rematado por una gran margarita y dos tallos laterales con otras menores. Aquí tallos y hojas se forman a base de diamantes en cabujón y facetados, y las esmeraldas y los rubíes se disponen en corona recreando los pétalos de la margarita junto a otros diamantes, destacando el central más grande y de talla oval. Una variedad de color y una disposición que intenta comportarle al ramo un claro sentido naturalista. Enmarcando las cartelas y los ramos se localizan en vertical alargados tallos rematados en otras margaritas, de factura y diseño muy parecido y recordando en esta ocasión a los pendientes alargados dieciochescos ${ }^{16}$. La peana se remata en un toro saliente decorado con otra guirnalda a base de flores de cuatro pétalos de diamantes con pistilo de rubí, que se enlazan entre pequeñas parejas de hojas alargadas con minúsculos diamantes ovalados (Figura 4).

El vástago se reduce a un nudo periforme invertido, decorado a base de cartelas verticales cinceladas que sirven de marco a otras margaritas de ocho pétalos de diamantes y una gruesa esmeralda central de talla tabla, a la que se le añaden en el tallo tres pequeños rubíes entre diamantitos. Un collarín de rubíes corona el nudo y sirve de basamento al estrecho y corto cuello donde se apoya la copa, el cual igualmente presenta otra guirnalda de flores, en este caso con pistilos de rubíes y esmeraldas en alternancia y talladas en cabujón. El resultado final de este vástago quizás resulte demasiado corto y algo desproporcionado en comparación a la peana y a la copa que soporta. No obstante, es evidente que es una solución y no una falta, pues con esta formulación del vástago se adaptaba perfectamente a las dimensiones de la urna de Valadier, destino final de esta obra.

Igualmente es deslumbrante el adorno de la ancha copa semiesférica. Otras cuatro grandes cartouches de rocalla, con sus roleos vegetales enroscados y encrespados en un diseño amplio y simétrico, ocupan toda su superficie ejecutados en un cincelado no muy elevado. Sobre estas cartelas se superponen nuevamente ramos de pedrería. Estos son muy parecidos a los de la peana, incluso en la disposición, tamaño y formas de las piedras, aunque con un diseño más abierto.

\footnotetext{
${ }_{15}$ Muller, 2012: 160-163. De Barcelona, 2005: 41 y 43v.

${ }_{16}$ Muller, 2012: 166 y 168.
} 
Igualmente, alargadas bandas florales aparecen entre los cartuchos de rocalla, así como en los ángulos de sus crestas se asoman detalles de flores con tallo y pétalos de diamantes, un rubí como pistilo y una minúscula esmeralda haciendo de hojita. Dos frisos de diamantes rematan la copa y la tapadera, el primero formado por pequeños diamantes tabla dispuestos en hilera, mientras que la cadeneta de hojas a manera de láurea se dispone sobre el arranque de la tapadera de perfil ligeramente bulboso. En ella, si bien las cartelas de rocalla y sus ramos sobrepuestos de pedrería son iguales, la diferencia viene marcada en los tallos intermedios rematados por margaritas, que en este caso presentan un lazo inferior en diamantes con una esmeralda talla tabla en el centro, semejante a los diseños de joyería de estos años ${ }^{17}$. En el centro, sobre una peana circular formada por una hilera de diamantes talla rosa, enmarcada por una guirnalda con detalles de esmeralda y rematada por una corona de rubíes, se levanta la cruz de traza bulbosa y cubierta también por pequeños diamantes, con cuatro rubíes en los ángulos y en los extremos de los brazos menores tres esmeraldas (Figura 5).

Un copón que en general evidencia la blandura y la plasticidad presentes en los diseños rococós, aunque también en él se advierten algunos detalles ornamentales, tanto en los cincelados como en los apliques de pedrerías, que delatan cambios hacia lo que será la estética neoclásica. En concreto, las cartelas de rocalla muestran la simetría de su decadencia y en los motivos de joyería se acercan a las modas que se impondrán a fines de siglo, sobre todo evidentes en las láureas de diamantes que perfilan la peana y la tapadera. Por lo tanto, si bien es una espléndida obra rococó, en ella también se respiran los aires de cambio que pronto se impondrán en la corte madrileña, especialmente durante el reinado de Carlos IV.

Otra cuestión que quedaría por determinar es a qué orfebre madrileño se podría adjudicar tan magistral creación. Desgraciadamente la documentación omite esta información y tampoco tenemos piezas similares de esta misma procedencia que nos permitan relacionarlo con un artífice concreto. No obstante, una pieza de tanta valía y coste, acorde con las novedades estéticas del momento, debió de salir de un maestro de primera fila, posiblemente de la platería real. Por ejemplo, se podría poner en relación con el francés Jean Farquet (†1774), quien trabajó desde 1750 para la Casa Real elaborando numerosos trabajos de oro y plata, al igual que para la nobleza y el clero de otros puntos de España ${ }^{18}$. De hecho, para la catedral de Santiago de Compostela y bajo el patrocinio del arzobispo Rajoy, entregó entre los años 1761 y 1762 un juego de cruz de altar y seis candelabros de oro, un copón de oro y diamantes, y una esclavina y bordón de oro para la imagen titular del templo, piezas todas ellas desaparecidas ${ }^{19}$. También se conocen las labores que como platero de oro realizó para Pedro de Alcántara

\footnotetext{
17 Muller, 2012: 161.

${ }_{18}$ Sobre el estudio detallado de su vida y obra, Cruz Valdovinos, 2017: 179-194.

19 Raposo Martínez, 2009: s. p.
} 
Pérez de Guzmán, XIV duque de Medina Sidonia (1724-1777). En concreto realizó un toisón de oro en 1769, tres escudos para gorras de volantes del duque y su señora en 1770, una cruz de oro esmaltada de la orden de la Inmaculada Concepción en 1772 y un anillo de oro con un brillante en forma de almendra junto a un toisón de brillantes en $1773^{20}$. La calidad de la obra catedralicia y su paralelismo con estos trabajos, más el importante currículum conocido al servicio de los reyes del referido orfebre, permiten presuponer su posible autoría, más cuando el canónigo Jerónimo José del Rosal siempre acudió en otros encargos a los mejores artistas de su tiempo, caso de Valadier en Roma, caso de Alexandre en Sevilla. No obstante, hasta que no aparezca un testimonio escrito que refrende esta hipótesis no podremos descartar a otros orfebres coetáneos que trabajaron en Madrid y que pudieron también estar detrás de esta magnífica creación. Entre ellos podemos citar al francés Leonardo Chopinot (1732-1799), quien comenzó a trabajar para María Luisa de Parma en 1769 y en 1773 fue nombrado platero de joyas de la Real Cámara, por lo que tampoco se podría descartar su paternidad sobre este copón de la catedral de Sevilla ${ }^{21}$. También destacó el romano Antonio Vendetti (1699-1796), el cual realizó trabajos de oro con pedrería, aunque destacó más por sus trabajos de plata y bronce para los Reales Sitios ${ }^{22}$. Sin olvidar a los orfebres españoles Fernando Velasco (h. 1720-1787), autor de la corona real en 1775, y Domingo de Urquiza (1730-1806), otro destacado platero de estas últimas décadas del siglo XVIII ${ }^{23}$. Lo cierto es que es difícil concretar su autoría sin un apoyo documental como quedó dicho, aunque lo que no hay dudas es que su inspiración se encuentra en la orfebrería europea del momento, pues precisamente los referentes semejantes los encontramos en obras como el cáliz de oro y pedrería de la capilla de San Genaro de Nápoles, labrado por el italiano Michele Lofrano en $1761^{24}$, o el cáliz de oro parisino conservado en la catedral de Calahorra (La Rioja), donado por el canónigo Juan Miguel de Mortela y Ziganda en 176525.

En definitiva, la pieza se convirtió en una de las joyas del tesoro, hasta el punto de ser referente y modelo para otras creaciones que fueron ejecutadas en Sevilla en ese momento. En concreto, cuando el mismo canónigo Jerónimo Ignacio del Rosal, como mayordomo y administrador de la capilla de la Antigua, quiso labrar un cáliz de oro y pedrería con el legado del indiano Diego Márquez Ortiz en 1776 para dicho recinto mariano, encomendó al platero José Alexandre una pieza semejante y, sin duda, inspirada en el copón madrileño ${ }^{26}$. El resultado

\footnotetext{
${ }^{20}$ Garrido Neva, 2013: 559-579.

${ }_{21}$ De Marcos Sánchez, 1987: 402-407. Aranda Huete, 2010: 105-124.

22 Vale, 2017: 401-417.

${ }^{23}$ Martín García, 2001: 149-162. Cruz/Nieva, 2018: 169-181.

24 Jorio/Paolillo, 2013: 193.

${ }^{25}$ Herrera Hernández, 2016: 565-567.

${ }^{26}$ Santos Márquez, 2018b: 118-121.
} 
final de este cáliz fue el de un elegante ejemplar aurífero adornado con diamantes, rubíes, esmeraldas y topacios, que aparentemente puede resultar bastante semejante al copón, pues presenta una fuerte inspiración en los modelos europeos. Pues bien, por esta misma razón, aún en el museo catedralicio en la actualidad se exhiben juntos y hasta no hace mucho tiempo se consideraron una creación conjunta salida de un mismo taller orfebre. Sin embargo, si nos detenemos en algunos detalles decorativos, tanto cincelados como de pedrería, nos encontramos claras diferencias al reflejar estos un acercamiento hacia modos y maneras propios de los inicios de un tiempo transitorio hacia el Neoclasicismo. Por lo tanto, con estos datos y por estas razones estéticas, se hace evidente que estamos ante dos piezas salidas de obradores diferentes, aunque ambas formen un soberbio ejemplo de las creaciones más singulares de la platería española de la década de 1770.

Fecha de recepción: 25 de octubre de 2019

Fecha de aceptación: 13 de abril de 2020

\section{BIBLIOGRAFÍA}

Aranda Huete, Amelia (2010): "Nuevos datos sobre Leonardo Chopinot, platero de oro de la segunda mitad del siglo XVIII". En: Rivas Carmona, Jesús/García Zapata, Ignacio (eds.): Estudios de Platería. San Eloy 2010. Murcia: Universidad de Murcia, pp. 105-124.

Cruz Valdovinos, José Manuel (1992): Cinco siglos de platería sevillana. Sevilla: Tabapress.

(2017): "El Platero Real francés Juan Farquet (†1774)". En: Rivas Carmona, Jesús/García Zapata, Ignacio (eds.): Estudios de Platería. San Eloy 2017. Murcia: Universidad de Murcia, pp. 179-194.

Cruz Valdovinos, José Manuel/Nieva Soto, Pilar (2018): "El platero real Fernando Velasco (h. 1720-1787)". En: Rivas Carmona, Jesús/García Zapata, Ignacio (eds.): Estudios de Platería. San Eloy 2018. Murcia: Universidad de Murcia, pp. 169-181.

De Barcelona, Fray Cosme (2005): Libro de Joyas de Nuestra Señora Santa María de Guadalupe. Edición Facsimilar del Códice 83 del Real Monasterio de Santa María de Guadalupe. Mérida: Ediciones Guadalupe.

De Marcos Sánchez, Rafael (1987): "Influencia francesa en la joyería de la corte española: Leonardo Chopinot”. En: Bonet Correa, Antonio (coord.): El arte en las Cortes Europeas del siglo XVIII. Madrid: Comunidad de Madrid, pp. 402-407.

Garrido Neva, Rocío (2013): "Dibujos de joyas para Pedro de Alcántara Pérez de Guzmán y Mariana de Silva, duques de Medina Sidonia”. En: Laboratorio de Arte, 25, vol. II, pp. 559-579. 
Herrera Hernández, Victoria Eugenia (2017): El arte de la platería en la Catedral de Calahorra (La Rioja). Siglos XV-XIX. Tesis doctoral. Logroño: Universidad de la Rioja.

Jorio, Paolo/Paolillo, Ciro (2013): Il Tesoro di Napoli. I capolavori del Museo di San Genaro. Milán: Skira.

Martín García, Fernando (2001): "El cargo de Platero Real”. En: Rivas Carmona, Jesús/García Zapata, Ignacio (eds.): Estudios de Platería. San Eloy 2001. Murcia: Universidad de Murcia, pp. 149-162.

Muller, Priscilla E. (2012): Joyas en España 1500-1800. Madrid: Ediciones El Viso.

Palomero Páramo, Jesús (1985): "La platería en la catedral de Sevilla". En: AA.VV.: La Catedral de Sevilla. Sevilla: Guadalquivir Ediciones, pp. 575645.

Raposo Martínez, Javier (2009): "Mecenazgo y gusto artístico del arzobispo compostelano Bartlomé Rajoy y Losada (1690-1772)". En: Congreso internacional Imagen y Apariencia. Murcia: Universidad de Murcia (versión electrónica sin paginar). https://digitum.um.es/digitum/handle/10201/44648 (19-11-2019).

Santos Márquez, Antonio Joaquín (2008): Los Ballesteros. Una familia de plateros en la Sevilla del quinientos. Sevilla: Diputación de Sevilla.

_- (2018a): "La reforma del trono de octavas de la catedral de Sevilla entre 1770 y 1772”. En: Rivas Carmona, Jesús/García Zapata, Ignacio (eds.): Estudios de Platería. San Eloy 2018. Murcia: Universidad de Murcia, pp. 509-524.

- (2018b): José Alexandre y Ezquerra y el triunfo de la rocalla en la platería sevillana. Sevilla: Diputación de Sevilla.

Sanz Serrano, María Jesús (1976): La orfebrería sevillana del Barroco. Sevilla: Diputación de Sevilla, vol. II.

Vale, Teresa Leonor (2017): "La controversia en torno a Antonio Vendetti (16991796), un platero y broncista entre Roma y Madrid. La importancia del dibujo y del modelado como expresión y habilidad de los plateros en el siglo XVIII”. En: Quintana, 17, pp. 401-417. 


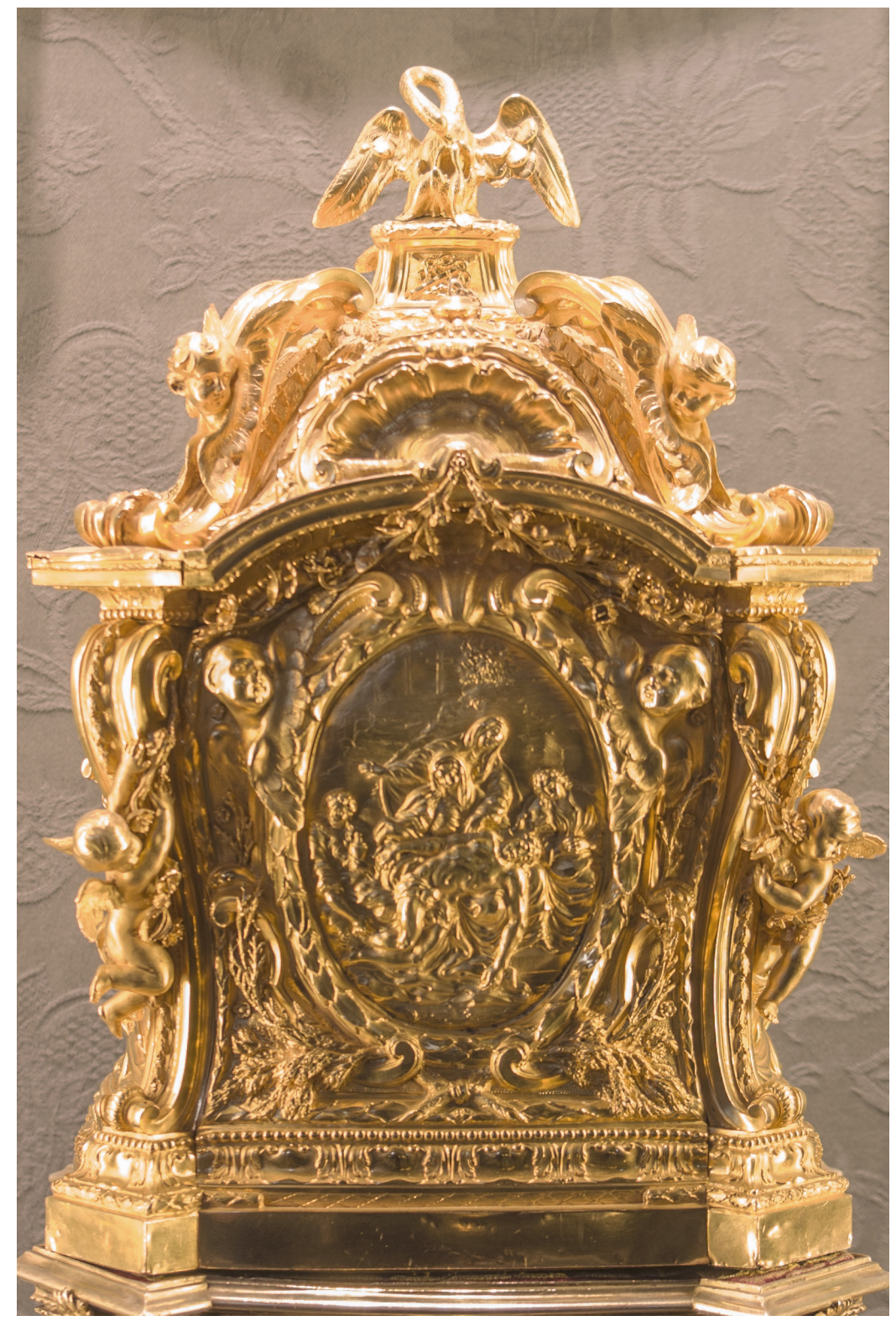

Figura 1. Luigi Valadier, Urna de oro, 1771, catedral de Sevilla. 


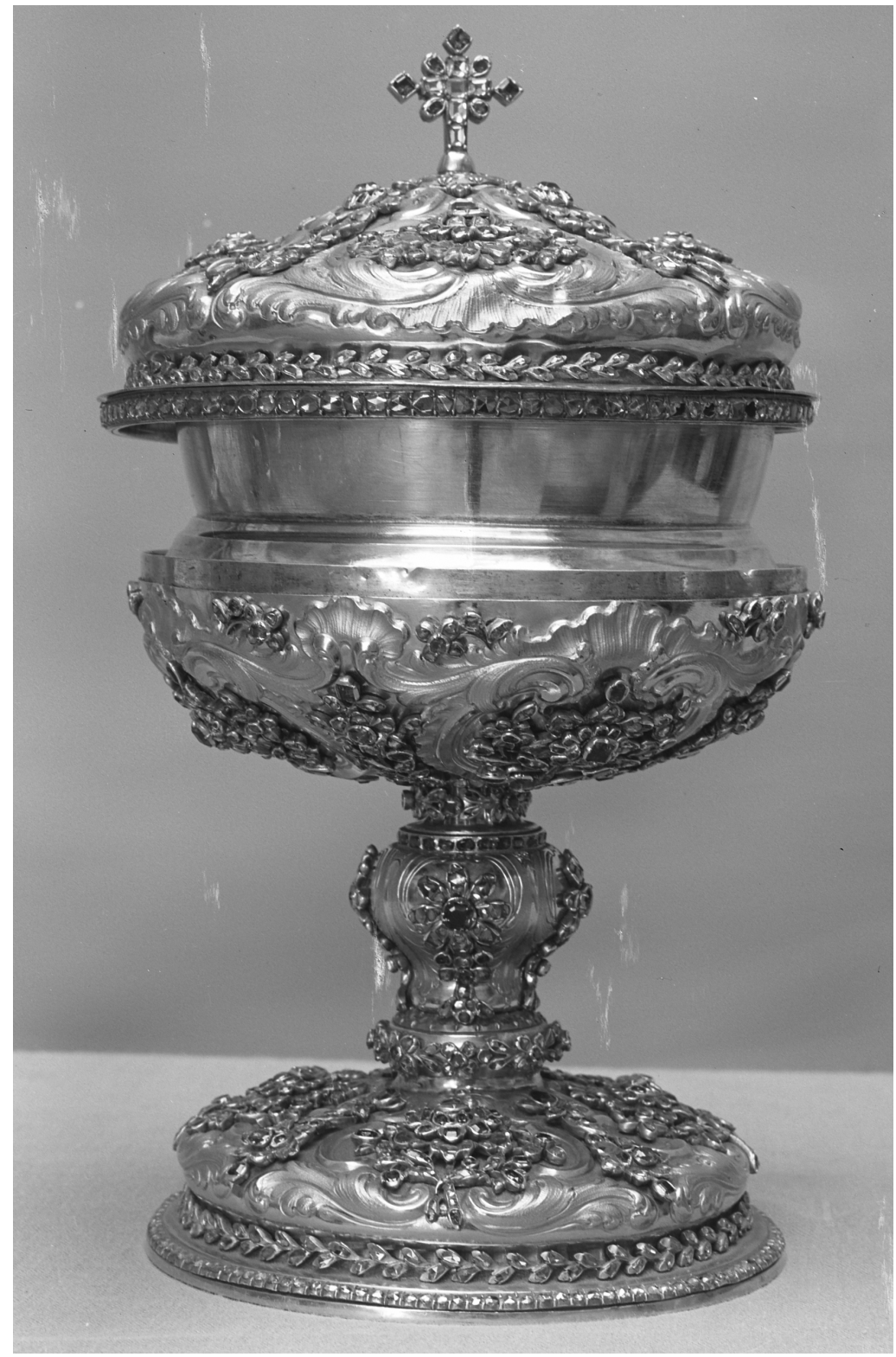

Figura 2. Anónimo madrileño, Copón de oro y pedrería con la copa de plata dorada en su interior, 1772, catedral de Sevilla. Fototeca del Laboratorio de Arte, Universidad de Sevilla (fotógrafo y fecha de ejecución desconocida, $\mathrm{n}^{\circ}$ de registro: LANV3_015831). 


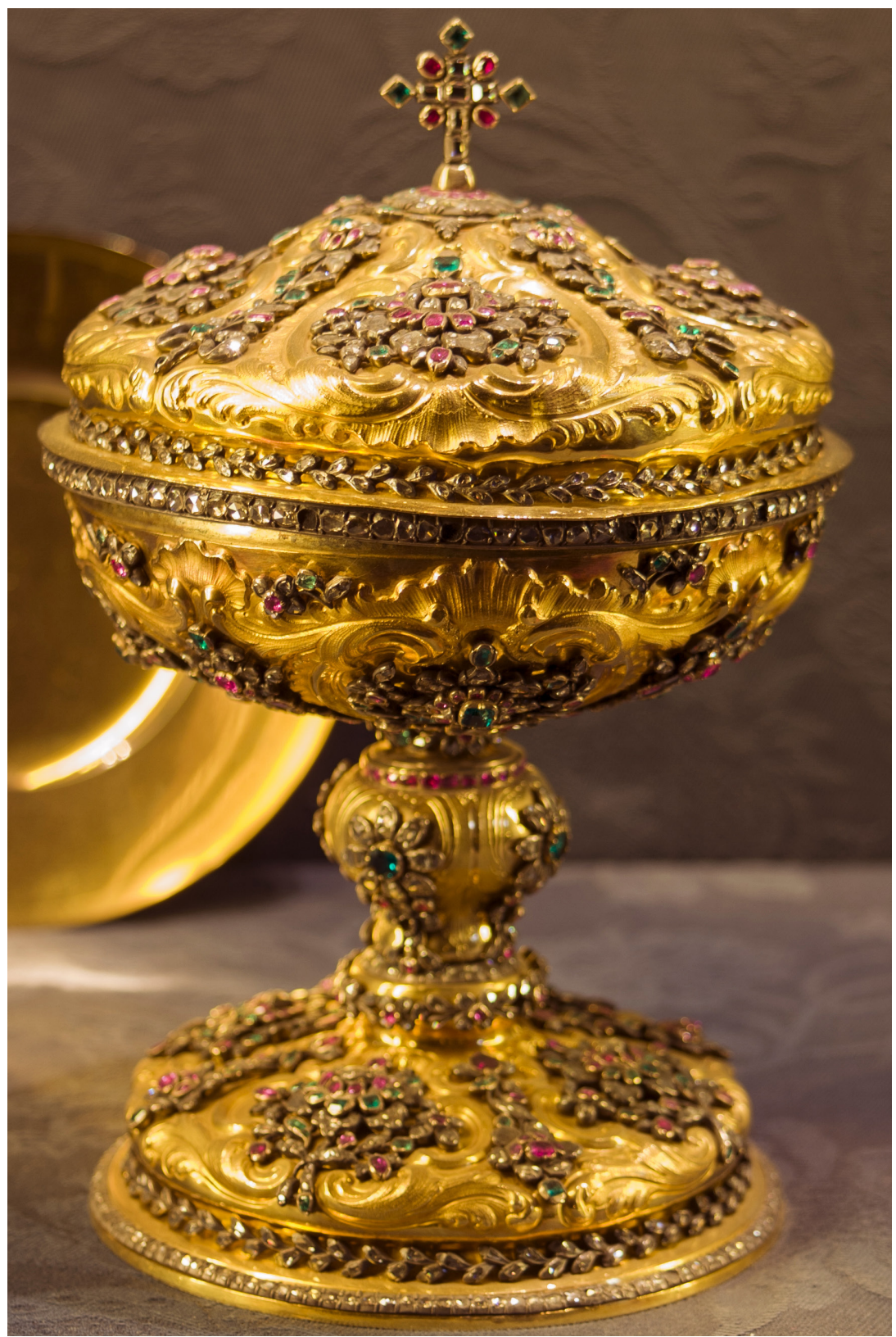

Figura 3. Anónimo madrileño, Copón de oro y pedrería, 1772, catedral de Sevilla.

LABORATORIO DE ARTE 32 (2020), pp. 351-364, ISSN 1130-5762 e-ISSN 2253-8305 - DOI http://dx.doi.org/10.12795/LA.2020.i32.18 


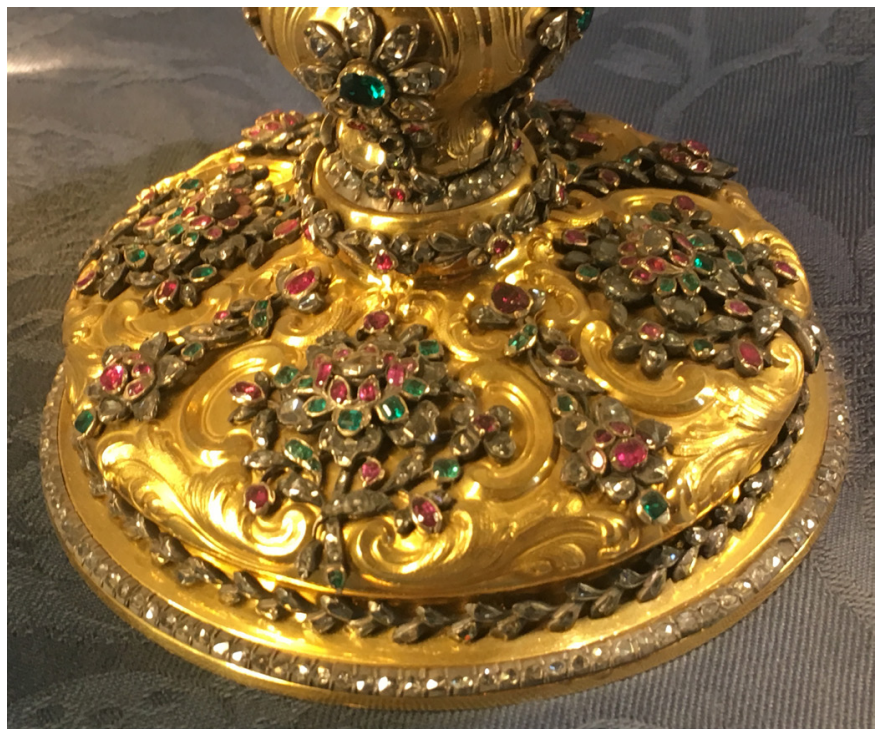

Figura 4. Anónimo madrileño, Copón de oro y pedrería (detalle de la peana), 1772, catedral de Sevilla.

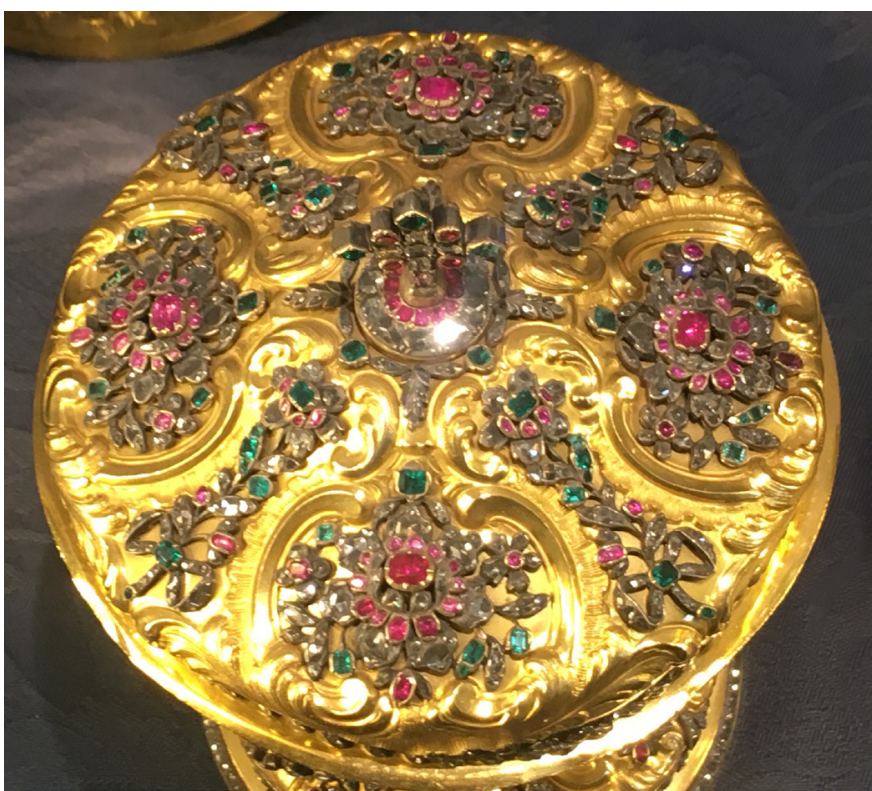

Figura 5. Anónimo madrileño, Copón de oro y pedrería (detalle de la tapadera), 1772, catedral de Sevilla. 